\title{
A PRÁTICA COMO COMPONENTE CURRICULAR NOS CURSOS DE LICENCIATURA EM MATEMÁTICA DO IFSP \\ Nicole Faria Costa ${ }^{1}$ Graziela Marchi Tiago²
}

Resumo: Por determinação da Lei 11.892/2008, 20\% das vagas dos Institutos Federais devem ser destinadas a cursos de licenciatura e programas especiais de formação pedagógica com vistas à formação de professores para a educação básica, com ênfase nas áreas de ciências, matemática e educação profissional (art. $8^{\circ}$ ). Estudos voltados às propostas formativas que vêm sendo oferecidas mostram-se essenciais à melhoria delas. Dentre as dificuldades enfrentadas pelos cursos de licenciatura estão em interpretarem os significados da Prática como Componente Curricular (PCC), e estas dificuldades já se expressam inclusive pelas diferentes formas de sua implementação nos projetos pedagógicos dos cursos. Assim, os objetivos deste trabalho são contribuir com a construção de uma concepção de PCC e também fornecer um panorama de como esta PCC está inserida nos Projetos Pedagógicos de Curso (PPC), mais especificamente cursos de Licenciatura em Matemática ofertados nos câmpus do IFSP.

Palavras-chave: Prática como Componente Curricular (PCC); Licenciatura em Matemática; IFSP.

\footnotetext{
${ }^{1}$ Instituto Federal de Educação, Ciência e Tecnologia de São Paulo/IFSP, Brasil. E-mail: nicolefariac@gmail.com.

2 Instituto Federal de Educação, Ciência e Tecnologia de São Paulo/IFSP, Brasil. E-mail: graziela@ifsp.edu.br.
} 